\title{
Impaired discrimination learning in mice lacking the NMDA receptor NR2A subunit
}

\author{
Jonathan L. Brigman, ${ }^{1,5}$ Michael Feyder, ${ }^{1}$ Lisa M. Saksida, ${ }^{2,3}$ Timothy J. Bussey, ${ }^{2,3}$ \\ Masayoshi Mishina, ${ }^{4}$ and Andrew Holmes ${ }^{1}$ \\ ${ }^{1}$ Section on Behavioral Science and Genetics, Laboratory for Integrative Neuroscience, National Institute on Alcoholism \\ and Alcohol Abuse, National Institutes of Health, Rockville, Maryland 20852, USA; ${ }^{2}$ Department of Experimental Psychology, \\ University of Cambridge, Cambridge CB2 3EB, United Kingdom; ${ }^{3}$ The Medical Research Council and Wellcome Trust Behavioral \\ and Clinical Neuroscience Institute, Cambridge CB2 3EB, United Kingdom; ${ }^{4}$ Department of Molecular Neurobiology and \\ Pharmacology, Graduate School of Medicine, University of Tokyo, Tokyo 113-0033, Japan
}

\begin{abstract}
$N$-Methyl-D-aspartate receptors (NMDARs) mediate certain forms of synaptic plasticity and learning. We used a touchscreen system to assess NR2A subunit knockout mice (KO) for (1) pairwise visual discrimination and reversal learning and (2) acquisition and extinction of an instrumental response requiring no pairwise discrimination. NR2A KO mice exhibited significantly retarded discrimination learning. Performance on reversal was impaired in NR2A $\mathrm{KO}$ mice during the learning phase of the task; with no evidence of heightened perseverative responses. Acquisition and extinction of an instrumental behavior requiring no pairwise discrimination was normal in NR2A KO mice. The present findings demonstrate a significant and selective deficit in discrimination learning following loss of NR2A.
\end{abstract}

Activation of $\mathrm{N}$-methyl-D-aspartate receptors (NMDARs) initiates a cascade of molecular events underlying synaptic plasticity and memory formation. Genetic or pharmacological inactivation of NMDARs prevents the induction of some forms of long-term potentiation (LTP) and long-term depression (LTD) (Malenka and Bear 2004) and impairs rodent learning on a range of tasks (Nakazawa et al. 2004; Bannerman et al. 2006).

NMDARs are heteromers composed of an obligatory NR1 subunit, plus varying combinations of NR2 (NR2A-NR2D) and sometimes NR3 subunits (Laube et al. 1998; Rosenmund et al. 1998). NR2A and NR2B subunits are differentially expressed over development, with NR2B predominating in the mouse brain until NR2A expression increases from the second postnatal week (Liu et al. 2004). NMDAR subunits also contribute different physiological properties to NMDAR and differentially interact with intracellular postsynaptic scaffolding and signaling molecules (Cull-Candy et al. 2001; Kohr 2006). However, the precise role of NR2A and NR2B in learning and memory remains unclear due to a lack of selective pharmacological compounds, particularly for NR2A (Neyton and Paoletti 2006; Kash and Winder 2007).

Recent work has shown that the relative ratio of NR2A/ NR2B is affected by sensory experience and learning, as well as environmental factors that impact learning such as sleep deprivation and stress (Baker and Kim 2002; Kart-Teke et al. 2006; Kopp et al. 2007). The shortening of synaptic NMDAR-mediated currents that correlates with increased developmental NR2A expression can be delayed by sensory deprivation (Carmignoto and Vicini 1992), while sensory input in previously deprived mice causes rapid synaptic insertion of NMDAR with a high NR2A/ NR2B ratio and an increase in the threshold for LTP induction in visual cortex (Kirkwood et al. 1996; Quinlan et al. 1999). Along similar lines, successful olfactory discrimination learning in rats correlates with an increase in the NR2A/NR2B ratio, a shortening of NMDAR currents, and an increase in the LTP-induction

${ }^{5}$ Corresponding author.

E-mail brigmanj@mail.nih.gov; fax (301) 480-1952.

Article is online at http://www.learnmem.org/cgi/doi/10.1101//m.777308. threshold in cortical slices (Philpot et al. 2003; Quinlan et al. 2004; Lebel et al. 2006). On the basis of these data, Lebel, Quinlan, and colleagues have proposed that a relative increase in NR2A serves to stabilize memories by constraining excessive synaptic plasticity (Quinlan et al. 2004).

Supporting the contribution of NR2A to synaptic and behavioral plasticity, targeted gene knockout (KO) of NR2A or its C-terminal domain is sufficient to impair hippocampal LTP and cause learning deficits on the Morris water maze and certain forms of Pavlovian fear conditioning (Sakimura et al. 1995; Ito et al. 1996; Kishimoto et al. 1997; Kiyama et al. 1998; Sprengel et al. 1998). To date, NR2A KO mice have not been tested on instrumental associative learning tasks. These tasks require incremental learning over trials, making them well-suited for evaluating the ability of NR2A KO mice to progressively acquire and retain stable associations. Positively reinforced instrumental learning tasks such as the touchscreen method used here also go some way to circumvent the strong aversive component inherent in the Morris water maze and fear conditioning; an important factor given abnormal anxiety-like behavior and stress reactivity in NR2A KO mice (Miyamoto et al. 2001; Boyce-Rustay and Holmes 2006b). In the present study, we sought to further elucidate the role of NR2A in mediating associative learning by testing NR2A $\mathrm{KO}$ mice on appetitive pairwise visual discrimination and reversal learning tasks and, for comparison, acquisition and extinction of a simple instrumental response that did not require pairwise discrimination.

NR2A mutant mice were generated as previously described (Sakimura et al. 1995). For the present study, the NR2A null mutation was backcrossed into the C57BL/6J strain for $>10$ generations to produce a congenic C57BL/6J genetic background. Analysis of 150 SNP markers at $\sim 15-20-\mathrm{Mb}$ intervals across all autosomal chromosomes confirmed $>99 \%$ C57BL/6J congenicity in the mutant line (JRS Allele Typing Services, The Jackson Laboratory, Bar Harbor, ME) (Boyce-Rustay and Holmes 2006a). To avoid abnormalities resulting from genotypic differences in neonatal environment (Holmes et al. 2005), NR2A KO, heterozygous NR2A (HET), and wild-type (WT) mice were generated from 
HET $\times$ HET matings. Mice were bred at The Jackson Laboratory, shipped to the NIH at 7-9 wk old, and tested from 10 wk old. Males and females were used and housed in groups of two to four with same-sex littermates in a temperature- and humiditycontrolled vivarium under a 12-h light/dark cycle (lights on at 06:00 h). The number of mice tested is given in the figure legends.

Learning was assessed in a touchscreen-based operant system described previously for rats (Bussey et al. 2001) and mice (Brigman et al. 2006; Izquierdo et al. 2006). The operant chamber measuring $21.6 \times 17.8 \times 12.7 \mathrm{~cm}$ (model no. ENV-307W; Med Associates) was housed within a sound and light attenuating box (Med Associates). The grid floor of the chamber was covered with solid Plexiglas to facilitate ambulation. A pellet dispenser delivering 14-mg dustless pellets (no. F05684; BioServ) into a pellet magazine located at one end of the chamber. At the opposite end of the chamber there was a touch-sensitive screen (Light Industrial Metal Cased TFT LCD Monitor; Craft Data Limited), a house light, and a tone generator. The touchscreen was covered by a black Plexiglas panel that had $2 \times 5 \mathrm{~cm}$ windows separated by $0.5 \mathrm{~cm}$ and located at a height of $6.5 \mathrm{~cm}$ from the floor of the chamber. Stimuli presented on the screen were controlled by custom software (MouseCat; L.M. Saksida) and visible through the windows ( 1 stimulus/window). Nosepokes to the stimuli were detected by the touchscreen and recorded by the MouseCat software.

Body weights were slowly reduced and then maintained at $85 \%$ of free-feeding. Prior to exposure to the testing apparatus, mice were acclimated to the $14-\mathrm{mg}$ pellet food reward by provision of $\sim 10$ pellets per mouse in the home cage for $1-3 \mathrm{~d}$. They were then acclimated to the operant chamber and taking rewards from the pellet magazine by being placed in the chamber with pellets freely available in the magazine. Apparatus habituation was indicated by eating 10 pellets in 30 min. Mice then underwent Pavlovian autoshaping. Variously shaped stimuli were presented in the touchscreen windows (1 per window) for $10 \mathrm{sec}$ (intertrial interval [ITI] $15 \mathrm{sec}$ ). The disappearance of the stimuli coincided with provision of a single-pellet food reward. To further reinforce the conditioned association between the stimuli and reward, pellet delivery was concomitant with illumination of the pellet magazine and the presentation of a 2 -sec $65-\mathrm{dB}$ tone. The mouse was required to eat the pellet in the pellet magazine (detected as a single head entry) in order for the next trial to commence. Successful autoshaping was indicated by eating 30 pellets within a 30-min session.

Prior to discrimination learning, mice first underwent three phases of instrumental pre-training (Izquierdo et al. 2006). Phase 1: To obtain a reward, the mouse was required to respond to a stimulus (variously shaped) that appeared in one of the two windows (spatially pseudorandomized) and remained on the screen until a response was made. Phase 2: This was the same as phase 1 , except that the mouse was now required to initiate a new trial by making a head entry into the pellet magazine between trials. Phase 3: This was the same as phase 2 but was introduced to discourage indiscriminate touching of the screen by signaling nosepokes at the blank window with a 5-sec timeout period during which the house light was extinguished. Punishment was followed by correction trials in which the same stimulus and spatial configuration was presented until a correct response was made. Each phase consisted of 30-trial sessions (15 sec ITI) administered 1 session/day. The mouse was required to perform 90\% correct responses (excluding correction trials) to progress through each phase and then onto discrimination learning. The effect of genotype on number of sessions to complete habituation, autoshaping, and each pre-training phase was analyzed using analysis of variance (ANOVA).
For discrimination learning, two novel equiluminant stimuli (see Bussey et al. 2001; Izquierdo et al. 2006) were presented, one per window. Responses at one stimulus (correct) resulted in reward; responses at the other stimuli (incorrect) resulted in a 5-sec timeout with the house light extinguished. Stimuli remained on screen until a response was made. Designation of the correct and incorrect stimuli was counterbalanced across genotypes. Within-session, left versus right spatial presentation of the correct and incorrect stimuli was pseudorandomized, with a given configuration occurring less than four times consecutively. For reversal learning (commencing the day after reaching criterion discrimination), the correct versus incorrect designation of stimuli was reversed (i.e., previously rewarded stimulus now incorrect, and vice versa). Discrimination and reversal sessions consisted of 30 discrete trials ( $15 \mathrm{sec}$ ITI). A trial is defined as the first presentation of a stimulus pair after a correct response has been made in either a first presentation trial or a correction trial. The criterion was performance at an average of $85 \%$ correct responses on first presentation trials over two consecutive sessions (at least $83 \%$ on any one session). Mice were offered a maximum of 60 sessions.

ANOVA, followed by Newman-Keuls post hoc tests, was used to analyze the effect of genotype on total (first presentation) trials, total incorrect responses (on first presentation trials), total correction trials, and total omitted (first presentation) trials to attain criterion, as well as average response reaction time and reward retrieval latency. Performance early during reversal when percent correct responses are low is characterized by perseveration at the previously rewarded stimulus (Jones and Mishkin 1972; Bussey et al. 1997; Chudasama and Robbins 2003). Therefore, we categorized reversal sessions according to whether performance was $<50 \%$ correct or $\geq 50 \%$ correct and calculated the total number of trials committed in each category. Trials committed on $<50 \%$ correct reflect performance when perseveration is relatively high. Trials committed on $\geq 50 \%$ correct reflect performance when perseveration is relatively low and learning is high. To further examine perseverative responding on the reversal problem, we calculated a "perseveration index": operationally defined as the ratio of correction trials to incorrect responses (on first presentation trials).

A separate cohort was tested for the acquisition and extinction of simple instrumental response in which the mouse must learn to respond to stimuli on the screen but is not required to make a discrimination to be rewarded. Mice first underwent habitation, autoshaping, and the first two phases of pre-training as above. They were then required to respond to a stimulus to obtain a pellet: two stimuli were presented $\left(1 \times 2.8 \mathrm{~cm}^{2}\right.$ white square per window) with a touch at either resulting in reward. Stimuli remained on the screen until a response was made. Sessions consisted of 30 trials ( $5 \mathrm{sec}$ ITI). The acquisition criterion was defined as performing 30 trials within 12.5 min on each of five consecutive sessions. The response was then extinguished (i.e., no reward for touches) to a criterion of two consecutive sessions of at least $77 \%$ trial omissions. The effect of genotype on number of sessions to attain acquisition and extinction criteria, as well as average response reaction time and latency of reward retrieval, was analyzed using analysis of variance (ANOVA). There was no significant interaction between genotype and sex, nor any main effect of sex, for any dependent measure, and data were collapsed across sex for analysis.

Results showed that genotypes did not differ in the number of sessions taken to complete habituation, autoshaping, or any phase of pre-training, although $\mathrm{KO}$ mice showed a trend for progressing more rapidly through pre-training phase 1 than WT or HET mice (Table 1) (note: $1 \mathrm{KO}$ and 3 HET mice were excluded from pre-training due to high omission rates). All mice tested 
Table 1. Apparatus habituation, Pavlovian autoshaping, and instrumental pre-training in mice lacking NR2A

\begin{tabular}{lrrr}
\hline & \multicolumn{1}{c}{ WT } & \multicolumn{1}{c}{ HET } & \multicolumn{1}{c}{ KO } \\
\hline Habituation & $1.0 \pm 0$ & $1.3 \pm 0.2$ & $1.2 \pm 0.1$ \\
Pavlovian autoshaping & $3.3 \pm 1.2$ & $6.4 \pm 2.1$ & $5.8 \pm 3.0$ \\
Pre-training phase 1 & $12.3 \pm 4.5$ & $14.11 \pm 4.6$ & $4.6 \pm 1.1$ \\
Pre-training phase 2 & $1.6 \pm 0.3$ & $1.6 \pm 0.2$ & $1.8 \pm 0.4$ \\
Pre-training phase 3 & $13.6 \pm 2.8$ & $14.7 \pm 3.2$ & $17.9 \pm 4.1$ \\
\hline
\end{tabular}

Genotypes did not differ in performance at any phase. $n=6 / 9$ per genotype. Data are mean + SEM number of sessions to attain criterion.

attained the performance criterion for discrimination learning. However, $\mathrm{KO}$ mice required significantly more trials to learn the discrimination (ANOVA effect of genotype: $F_{(2,19)}=4.48$, $P<0.05$; post hoc tests, $P<0.01$ ) (Fig. $1 \mathrm{~A}$ ) and made significantly more incorrect responses in doing so (genotype: $F_{(2,19)}=4.31$, $P<0.05$; post hocs, $P<0.01$ ) (Fig. 1B), as compared to WT or HET mice. There was a nonsignificant trend for a genotype difference in correction errors $\left(F_{(2,19)}=3.16, P=0.07\right)$ (Fig. 1C).
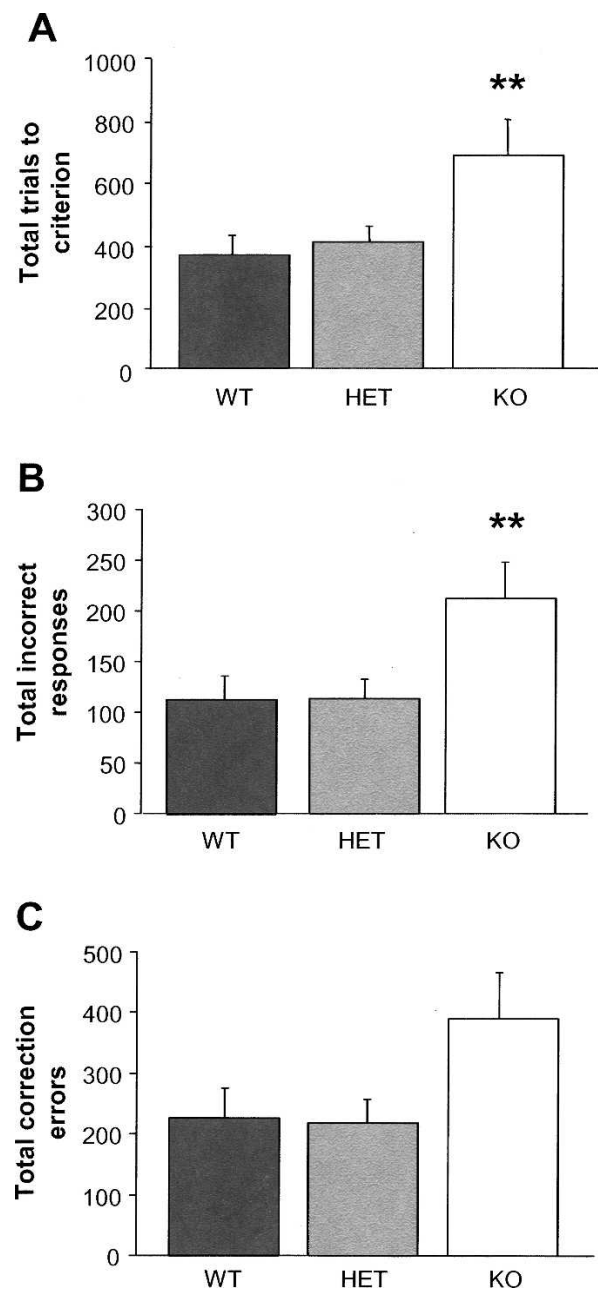

Figure 1. Impaired pairwise visual discrimination learning in NR2A KO mice. $(A) \mathrm{KO}$ mice committed more trials than WT or HET mice to reach criterion. (B) KO mice committed more incorrect responses than WT or HET mice to reach criterion. (C) KO mice showed a nonsignificant trend for committing more correction errors than WT or HET mice. $n=6-8$ per genotype. Data in Figures $1-3$ are means \pm SEM. ${ }^{* *} P<0.01$ vs. WT and HET.
Genotypes did not significantly differ in the number of trials omitted $(\mathrm{WT}=4.6 \pm 2.3, \mathrm{HET}=5.5 \pm 4.7, \mathrm{KO}=8.0 \pm 5.7)$, response reaction time $(\mathrm{WT}=8.0 \pm 0.9 \mathrm{sec}$, HET $=8.9 \pm 0.9$, $\mathrm{KO}=7.0 \pm 1.4)$, or latency to retrieve the reward $(\mathrm{WT}=3.5 \pm 0.8$ sec, $\mathrm{HET}=2.6 \pm 0.5, \mathrm{KO}=2.7 \pm 0.7$ ).

The KO mice were significantly impaired on the reversal task. They committed more trials (genotype: $F_{(2,18)}=8.05$, $P<0.01$; post hocs, $P<0.01$ ) (Fig. $2 \mathrm{~A}$ ) and made more incorrect responses (genotype: $F_{(2,18)}=6.30, P<0.05$; post hocs, $P<0.01$ ) (Fig. 2B) and correction errors (genotype: $F_{(2,18)}=4.61, P<0.05$; post hocs, $P<0.01$ ) (Fig. $2 \mathrm{C}$ ) than WT or HET mice. For sessions in which percent correct scores were $\geq 50 \%$, $\mathrm{KO}$ mice committed more trials than WT mice (genotype: $F_{(2,18)}=8.74, P<0.01$; post hocs, $P<0.01$ ), while genotypes were no different during sessions where percent correct scores were $<50 \%$ (genotype: $F_{(2,18)}=2.57, P=0.10$ ) (Fig. 2D). The perseveration index was greater during sessions when performance was $<50 \%$ than when it was $\geq 50 \%$, but was no different between genotypes $(<50 \%$, $\mathrm{WT}=4.4 \pm 0.8, \mathrm{HET}=3.1 \pm 0.5, \mathrm{KO}=2.9 \pm 0.9 ; \geq 50 \%$, $\mathrm{WT}=1.5 \pm 0.1, \mathrm{HET}=1.5 \pm 0.1, \mathrm{KO}=1.8 \pm 0.1$ ). Two of eight $\mathrm{KO}$ mice failed to attain criterion after 60 sessions, and their scores up to 60 sessions were included in the analysis. Genotypes did not differ in the number of trials omitted (WT $=35.1 \pm 13.4$, $\mathrm{HET}=66.8 \pm 23.3, \mathrm{KO}=31.8 \pm 10.0)$, response reaction time $(\mathrm{WT}=5.7 \pm 0.7 \mathrm{sec}, \mathrm{HET}=7.9 \pm 1.3, \mathrm{KO}=4.6 \pm 0.7)$, or reward retrieval latency $(\mathrm{WT}=2.1 \pm 0.2 \mathrm{sec}, \mathrm{HET}=2.9 \pm 0.8$, $\mathrm{KO}=2.0 \pm 0.2$ ).

There were no genotype differences in the trials taken to either acquire (Fig. 3A) or extinguish (Fig. 3B) an instrumental behavior that did not require discrimination. Rates of habituation, autoshaping, and instrumental pre-training prior to acquisition on this task were not different between genotypes (data not shown).

The major finding of the present study was impaired discrimination learning in NR2A KO mice. Specifically, NR2A KO mice were markedly slower than WT mice to acquire a pairwise visual discrimination, and when the reinforcement contingencies of the learned association were reversed, NR2A KO mice were significantly impaired relative to WT mice. This was due to deficient learning of the new association rather than impaired reversal per se, as genotypes performed at equivalent levels during reversal sessions when performance was low and perseveration high (i.e., <50\%) (Jones and Mishkin 1972; Bussey et al. 1997; Chudasama and Robbins 2003), while KO mice committed more trials and errors during sessions when performance was largely learning-related (i.e., >50\%). However, the possible contribution of increased perseverative responding and a more general deficit in cognitive flexibility in NR2A KO mice cannot be excluded.

Impaired discrimination and reversal learning in NR2A KO mice was not due to nonspecific motivation or sensorimotorrelated performance, as evidenced by normal scores on trial omissions, response reaction times, or reward retrieval latencies. Moreover, NR2A KO mice were no different from WT controls in the rate of acquisition and extinction of an instrumental touchscreen response that did not require pairwise stimulus discrimination. Finally, NR2A HET mice were unimpaired on any of these tests or in discrimination and reversal, demonstrating that NR2A haploinsufficiency was insufficient to disrupt learning.

The present findings support and extend previous evidence of impaired spatial reference memory and associative fear learning in NR2A KO mice (Sakimura et al. 1995; Ito et al. 1996; Kishimoto et al. 1997; Kiyama et al. 1998; Sprengel et al. 1998). The phenotypic profile of NR2A KO mice in our study is also highly reminiscent of recent pharmacological data showing that systemic administration of the noncompetitive NMDAR antagonist MK-801 significantly retarded acquisition on a pairwise olfactory 
A

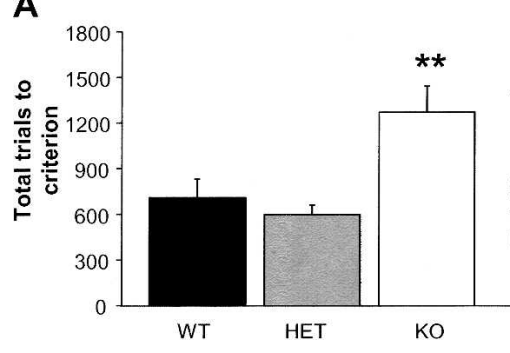

B

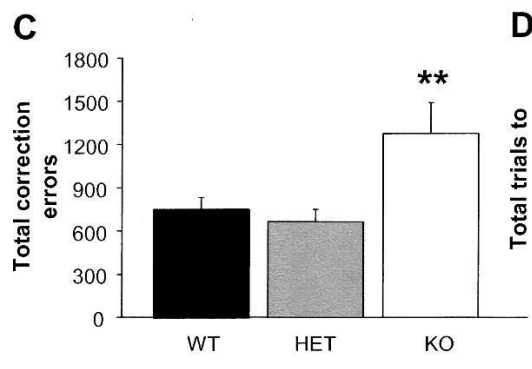

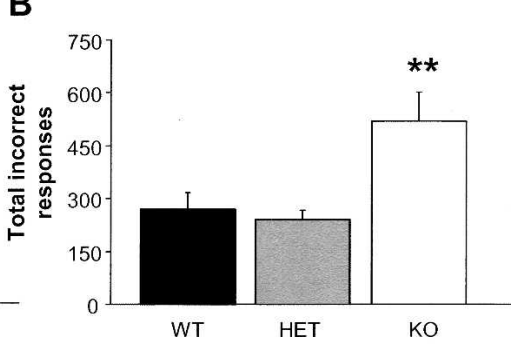

D

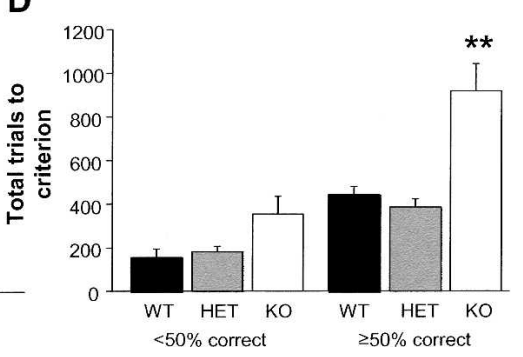

Figure 2. Impaired pairwise visual discrimination learning during reversal in NR2A KO mice. $(A) \mathrm{KO}$ mice committed more trials than WT or HET mice to reach criterion. (B) KO mice committed more incorrect responses than WT or HET mice to reach criterion. (C) KO mice committed more correction errors than WT or HET mice. $(D)$ KO mice committed more trials than WT or HET mice to reach criterion on sessions when percent correct scores were $\geq 50 \%$ but not $<50 \%$. $n=6-8$ per genotype. ${ }^{*} P<0.01$ versus WT and HET.

discrimination test in rats (Lebel et al. 2006). Interestingly, successful discrimination learning in untreated rats was associated with an increase in the NR2A/NR2B ratio in olfactory cortex, and this increase was blocked by treatment with the NMDAR antagonist MK-801 (Lebel et al. 2001, 2006). The loss of this molecular switch would be a plausible mechanism for the impaired discrimination learning seen in NR2A KO mice in the present study.

NR2A KO or MK-801 treatment in rats significantly retarded
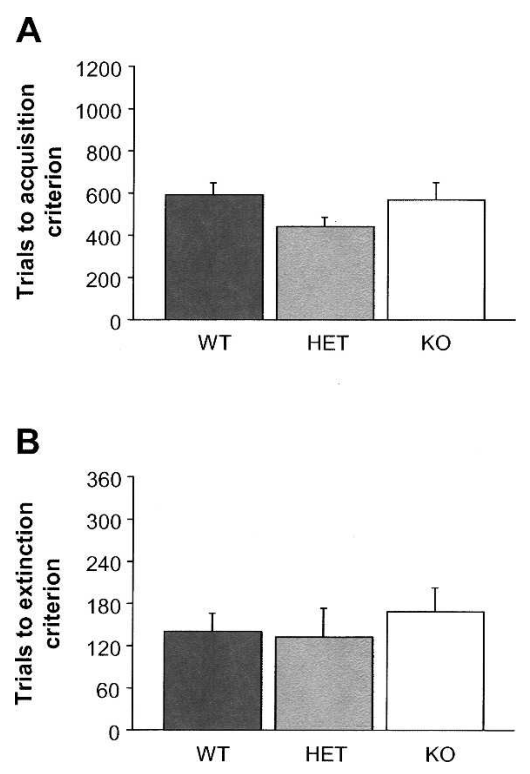

Figure 3. Normal acquisition and extinction of an instrumental behavior requiring no pairwise discrimination in NR2A KO mice. $(A)$ Genotypes did not differ in the number of trials to acquire the instrumental behavior. (B) Genotypes did not differ in the number of trials to extinguish the instrumental behavior. $n=8$ per genotype. the rate of discrimination learning, but neither manipulation completely prevented learning when animals were offered extended training. Thus, in the absence of an NR2A-mediated mechanism, alternative, albeit less efficient, molecular pathways are able to support learning. This is consistent with a wider literature showing that where NMDARs are important mediators of learning, as in the Morris water maze, alternative mechanisms can mitigate the effects of NMDAR inactivation under certain conditions (e.g., after pre-training) (for discussion, see Nakazawa et al. 2004; Bannerman et al. 2006). Furthermore, it is known that while both NR2A- and NR2B-containing NMDARs subserve synaptic plasticity, this only holds for certain forms of plasticity, and NR2A is clearly not obligatory for LTP (Weitlauf et al. 2005).

In conclusion, our study provides evidence of a significant and selective deficit in associative learning in mice lacking NR2A. Given loss of NMDAR expression in aging (Magnusson 2001; Ontl et al. 2004) and neuropsychiatric disorders with a major cognitive component, such as schizophrenia (Beneyto et al. 2007), Alzheimer's disease (Maragos et al. 1987; Wang et al. 2000; Sze et al. 2001), and mood disorders (Nowak et al. 1995; Beneyto et al. 2007), the present data could provide insight into the contribution of NMDAR to the pathophysiology of these disorders.

\section{Acknowledgments}

This work was supported by the National Institute on Alcohol Abuse and Alcoholism Intramural Research Program.

\section{References}

Baker, K.B. and Kim, J.J. 2002. Effects of stress and hippocampal NMDA receptor antagonism on recognition memory in rats. Learn. Mem. 9: 58-65.

Bannerman, D.M., Rawlins, J.N., and Good, M.A. 2006. The drugs don't work-Or do they? Pharmacological and transgenic studies of the contribution of NMDA and GluR-A-containing AMPA receptors to hippocampal-dependent memory. Psychopharmacology 188: 552-566.

Beneyto, M., Kristiansen, L.V., Oni-Orisan, A., McCullumsmith, R.E., and Meador-Woodruff, J.H. 2007. Abnormal glutamate receptor expression in the medial temporal lobe in schizophrenia and mood disorders. Neuropsychopharmacology 32: 1888-1902.

Boyce-Rustay, J.M. and Holmes, A. 2006a. Genetic inactivation of the NMDA receptor NR2A subunit has anxiolytic- and antidepressantlike effects in mice. Neuropsychopharmacology 31: 2405-2414.

Boyce-Rustay, J.M. and Holmes, A. 2006b. Ethanol-related behaviors in mice lacking the NMDA receptor NR2A subunit. Psychopharmacology 187: 455-466.

Brigman, J.L., Padukiewicz, K.E., Sutherland, M.L., and Rothblat, L.A. 2006. Executive functions in the heterozygous reeler mouse model of schizophrenia. Behav. Neurosci. 120: 984-988.

Bussey, T.J., Muir, J.L., Everitt, B.J., and Robbins, T.W. 1997. Triple dissociation of anterior cingulate, posterior cingulate, and medial frontal cortices on visual discrimination tasks using a touchscreen testing procedure for the rat. Behav. Neurosci. 111: 920-936.

Bussey, T.J., Saksida, L.M., and Rothblat, L.A. 2001. Discrimination of computer-graphic stimuli by mice: A method for the behavioral characterization of transgenic and gene-knockout models. Behav. Neurosci. 115: 957-960.

Carmignoto, G. and Vicini, S. 1992. Activity-dependent decrease in NMDA receptor responses during development of the visual cortex. 
Science 258: 1007-1011.

Chudasama, Y. and Robbins, T.W. 2003. Dissociable contributions of the orbitofrontal and infralimbic cortex to Pavlovian autoshaping and discrimination reversal learning: Further evidence for the functional heterogeneity of the rodent frontal cortex. J. Neurosci. 23: $8771-8780$.

Cull-Candy, S., Brickley, S., and Farrant, M. 2001. NMDA receptor subunits: Diversity, development and disease. Curr. Opin. Neurobiol. 11: $327-335$.

Holmes, A., le Guisquet, A.M., Vogel, E., Millstein, R.A., Leman, S., and Belzung, C. 2005. Early life genetic, epigenetic and environmental factors shaping emotionality in rodents. Neurosci. Biobehav. Rev. 29: 1335-1346.

Ito, I., Sakimura, K., Mishina, M., and Sugiyama, H. 1996. Age-dependent reduction of hippocampal LTP in mice lacking $N$-methyl-D-aspartate receptor $\varepsilon 1$ subunit. Neurosci. Lett. 203: 69-71.

Izquierdo, A., Wiedholz, L.M., Millstein, R.A., Yang, R.J., Bussey, T.J., Saksida, L.M., and Holmes, A. 2006. Genetic and dopaminergic modulation of reversal learning in a touchscreen-based operant procedure for mice. Behav. Brain Res. 171: 181-188.

Jones, B. and Mishkin, M. 1972. Limbic lesions and the problem of stimulus-reinforcement associations. Exp. Neurol. 36: 362-377.

Kart-Teke, E., De Souza Silva, M.A., Huston, J.P., and Dere, E. 2006. Wistar rats show episodic-like memory for unique experiences. Neurobiol. Learn. Mem. 85: 173-182.

Kash, T. and Winder, D.G. 2007. NMDAR LTP and LTD induction: 2B or not 2B ... Is that the question? Debates Neurosci. 1: 79-84.

Kirkwood, A., Rioult, M.C., and Bear, M.F. 1996. Experience-dependent modification of synaptic plasticity in visual cortex. Nature 381: 526-528.

Kishimoto, Y., Kawahara, S., Kirino, Y., Kadotani, H., Nakamura, Y., Ikeda, M., and Yoshioka, T. 1997. Conditioned eyeblink response is impaired in mutant mice lacking NMDA receptor subunit NR2A. Neuroreport 8: 3717-3721.

Kiyama, Y., Manabe, T., Sakimura, K., Kawakami, F., Mori, H., and Mishina, M. 1998. Increased thresholds for long-term potentiation and contextual learning in mice lacking the NMDA-type glutamate receptor epsilon1 subunit. J. Neurosci. 18: 6704-6712.

Kohr, G. 2006. NMDA receptor function: Subunit composition versus spatial distribution. Cell Tissue Res. 326: 439-446.

Kopp, C., Longordo, F., and Luthi, A. 2007. Experience-dependent changes in NMDA receptor composition at mature central synapses. Neuropharmacology 326: 439-446.

Laube, B., Kuhse, J., and Betz, H. 1998. Evidence for a tetrameric structure of recombinant NMDA receptors. J. Neurosci. 18: 2954-2961.

Lebel, D., Grossman, Y., and Barkai, E. 2001. Olfactory learning modifies predisposition for long-term potentiation and long-term depression induction in the rat piriform (olfactory) cortex. Cereb. Cortex 11: $485-489$.

Lebel, D., Sidhu, N., Barkai, E., and Quinlan, E.M. 2006. Learning in the absence of experience-dependent regulation of NMDAR composition. Learn. Mem. 13: 566-570.

Liu, X.B., Murray, K.D., and Jones, E.G. 2004. Switching of NMDA receptor $2 \mathrm{~A}$ and $2 \mathrm{~B}$ subunits at thalamic and cortical synapses during early postnatal development. J. Neurosci. 24: 8885-8895.

Magnusson, K.R. 2001. Influence of diet restriction on NMDA receptor subunits and learning during aging. Neurobiol. Aging 22: 613-627.

Malenka, R.C. and Bear, M.F. 2004. LTP and LTD: An embarrassment of riches. Neuron 44: 5-21.

Maragos, W.F., Chu, D.C., Young, A.B., D'Amato, C.J., and Penney Jr., J.B. 1987. Loss of hippocampal $\left[{ }^{3} \mathrm{H}\right] \mathrm{TCP}$ binding in Alzheimer's disease. Neurosci. Lett. 74: 371-376.

Miyamoto, Y., Yamada, K., Noda, Y., Mori, H., Mishina, M., and Nabeshima, T. 2001. Hyperfunction of dopaminergic and serotonergic neuronal systems in mice lacking the NMDA receptor $\varepsilon 1$ subunit. I. Neurosci. 21: 750-757.

Nakazawa, K., McHugh, T.J., Wilson, M.A., and Tonegawa, S. 2004. NMDA receptors, place cells and hippocampal spatial memory. Nat. Rev. Neurosci. 5: 361-372.

Neyton, J. and Paoletti, P. 2006. Relating NMDA receptor function to receptor subunit composition: Limitations of the pharmacological approach. J. Neurosci. 26: 1331-1333.

Nowak, G., Ordway, G.A., and Paul, I.A. 1995. Alterations in the $\mathrm{N}$-methyl-D-aspartate (NMDA) receptor complex in the frontal cortex of suicide victims. Brain Res. 675: 157-164.

Ontl, T., Xing, Y., Bai, L., Kennedy, E., Nelson, S., Wakeman, M., and Magnusson, K. 2004. Development and aging of N-methyl-Daspartate receptor expression in the prefrontal/frontal cortex of mice. Neuroscience 123: 467-479.

Philpot, B.D., Espinosa, J.S., and Bear, M.F. 2003. Evidence for altered NMDA receptor function as a basis for metaplasticity in visual cortex. J. Neurosci. 23: 5583-5588.

Quinlan, E.M., Philpot, B.D., Huganir, R.L., and Bear, M.F. 1999. Rapid, experience-dependent expression of synaptic NMDA receptors in visual cortex in vivo. Nat. Neurosci. 2: 352-357.

Quinlan, E.M., Lebel, D., Brosh, I., and Barkai, E. 2004. A molecular mechanism for stabilization of learning-induced synaptic modifications. Neuron 41: 185-192.

Rosenmund, C., Stern-Bach, Y., and Stevens, C.F. 1998. The tetrameric structure of a glutamate receptor channel. Science 280: 1596-1599.

Sakimura, K., Kutsuwada, T., Ito, I., Manabe, T., Takayama, C., Kushiya, E., Yagi, T., Aizawa, S., Inoue, Y., Sugiyama, H., et al. 1995. Reduced hippocampal LTP and spatial learning in mice lacking NMDA receptor $\varepsilon 1$ subunit. Nature 373: 151-155.

Sprengel, R., Suchanek, B., Amico, C., Brusa, R., Burnashev, N., Rozov, A., Hvalby, O., Jensen, V., Paulsen, O., Andersen, P., et al. 1998. Importance of the intracellular domain of NR2 subunits for NMDA receptor function in vivo. Cell 92: 279-289.

Sze, C., Bi, H., Kleinschmidt-DeMasters, B.K., Filley, C.M., and Martin, L.J. 2001. N-Methyl-D-aspartate receptor subunit proteins and their phosphorylation status are altered selectively in Alzheimer's disease. I. Neurol. Sci. 182: 151-159.

Wang, Y., TesFaye, E., Yasuda, R.P., Mash, D.C., Armstrong, D.M., and Wolfe, B.B. 2000. Effects of post-mortem delay on subunits of ionotropic glutamate receptors in human brain. Brain Res. Mol. Brain Res. 80: 123-131.

Weitlauf, C., Honse, Y., Auberson, Y.P., Mishina, M., Lovinger, D.M. and Winder, D.G. 2005. Activation of NR2A-containing NMDA receptors is not obligatory for NMDA receptor-dependent long-term potentiation. J. Neurosci. 25: 8386-8390.

Received September 14, 2007; accepted in revised form December 6, 2007. 


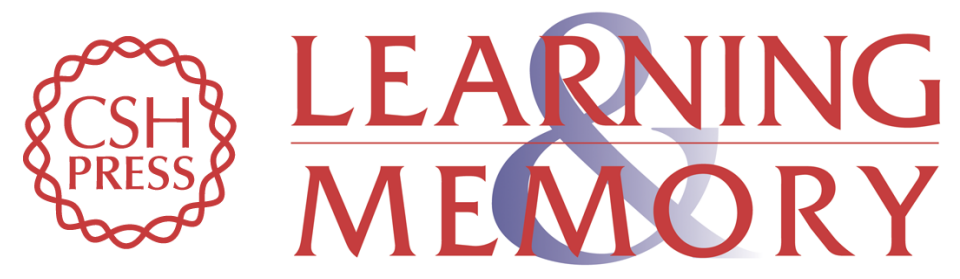

\section{Impaired discrimination learning in mice lacking the NMDA receptor NR2A subunit}

Jonathan L. Brigman, Michael Feyder, Lisa M. Saksida, et al.

Learn. Mem. 2008, 15:

Access the most recent version at doi:10.1101//m.777308

References This article cites 43 articles, 12 of which can be accessed free at:

http://learnmem.cshlp.org/content/15/2/50.full.html\#ref-list-1

License

Email Alerting Receive free email alerts when new articles cite this article - sign up in the box at the Service top right corner of the article or click here. 